the long-range detection of earthquakes, including short-period instruments. The established fundamentals of earth structure, upon which seismic wave propagation is dependent, are set forth, and traveltime tables for the major phases are discussed; graphs of the Gutenberg-Richter tables for four depths of earthquake focus, and published during 1934-39, are given. It is to be noted that an error of one second in determining the arrival time of the primary or $P$ phase will result in epicentral distance errors ranging from $8 \mathrm{~km}$. at a distance of $1,000 \mathrm{~km}$. to $22 \mathrm{~km}$. at a distance of $10,000 \mathrm{~km}$. Rather more than ten years ago, Gutenberg and Richter introduced the earthquake magnitude scale, based on measurements of seismograms, to replace the earthquake intensity scales used previously. This logarithmic magnitude scale is described in detail. An increase of one unit in magnitude signifies a 63 -fold increase in energy, and on the Gutenberg-Richter scale an earthquake of magnitude 5 would release $10^{21}$ ergs of energy. Copies of interpreted seismograms are given as illustrations in the publication.

\section{The Blue Sun of September 1950}

THE results of spectrophotometric observations of the blue sun, made at Edinburgh between $15 \mathrm{~h} .20 \mathrm{~m}$. and $15 \mathrm{~h} .25 \mathrm{~m}$. U.T. on September 26, 1950, have been described by R. Wilson (Mon. Not. Roy. Astro. Soc., 111, 5 ; 1951). The 36-in. Cassegrain reflector of the Royal Observatory was used with the two-glass prism train of the attached Hilger universal spectrograph, giving the respective dispersions 132, 45 and $28 \mathrm{~A} . / \mathrm{mm}$. at $H \alpha, H \beta$ and $H \gamma$. Very full details of the procedure and the deductions are given in the paper, at the end of which appears a summary of the conclusions. The layer causing the phenomenon was due to extensive forest fires in Alberta on September 23,1950 , the smoke from which was carried by upper winds to Europe, where the effect was quite different from that in America. Over the latter continent at various times and places there was complete darkness, and when the sun was visible it was purple or blue, while the scattered light in the sky produced shades of orange, purple or blue. Over Edinburgh on the afternoon of September 26 the smoke was observed, and the sun, seen quite clearly through the haze, was a deep indigo blue. According to E. M. Elsley (Weather, 6, 22 ; 1951), the scattering particles were globules of oil, caused by the distillation of wood, and the scattering theory predicted various features which were experimentally verified by Wilson's investigations. These particles were dielectric in nature and very homogeneous in size and constitution, and there appears to be the possibility that there was another system of particles in the layer, producing a neutral extinction. Using a relation deduced between the diameter and the refractive index of the scattering particles and assuming the latter to be about $1 \cdot 5$, which is near the value for most organic oils, the diameter of the particles would be of the order of one micron. If there was the other system of particles in the scattering layer, it is suggested that their most likely constitution was carbon, and it is possible that their size could be the same as that of the uniform dielectric particles. Communications in Nature of September 29, pp. 545 and 554, and December 22, p. 1086 (1951), also discussed this topic.

\section{Exhibition of Geometry at Chicago}

THE Illinois Institute of Technology has arranged an exhibition of geometry at the Chicago Museum of
Science and Industry, and Prof. Karl Menger has written an attractive 34-page guide-book, with the title "You will like Geometry". The most striking feature of this is the large number of beautiful diagrams. The subjects treated are very varied. There are simple constructions of plane geometry, including some of a puzzle type which do not appear in the usual text-books. There is also a section on the regular solids, including Kepler's star-faced solids and Poinsot's star-cornered solids. Other parts of the guide book deal with more advanced mathematics, such-as the theory of groups, which is introduced with reference to operations on triangles and other geometrical figures. An account is given of the 'universal curve', discovered by the author, which has the property that every curve of our space can be deformed into one of its parts. As the preface claims, "Geometry is amazing and ingenious and beautiful and profound; and, most important, it is alive and growing".

\section{Announcements}

'OPEN days' are being held at the Chemical Research Laboratory, Teddington, Middlesex, during September 23-26. Industrial firms wishing to send representatives and who are not already on the mailing list should apply to the Director, before August 31, for invitations for September 23 (afternoon), September 25 or 26 (morning or afternoon).

Pakistan's first seismological research station is now being built in Quetta with the technical assistance of Unesco. The new service would be grateful for reprints of seismological papers published before 1948 and for back numbers of journals, which should be sent to the Pakistan Meteorological Service, Geophysical Division, Kings Road, Quetta, Pakistan.

Messrs. Blundell Rules, Ltd., Chaul End Lane, Luton, Beds, have issued a small handbook of 22 pages (price $6 d$.) describing their range of slide rules, and giving examples of the uses of the various patterns. Thus, in addition to the usual rules in various styles graduated for simple mathematical operations, there are others with log-log scales, commercial calculators, electricians' scales with appropriate quantities, and a timber calculator. Most of these scales are made entirely of a white plastic material, based on vinyl chloride-vinylidene chloride copolymers, with a 'satin' finish. It is claimed to be resistant to water, most chemicals and fungi. It is strong, and the scales are sharp and clear; in some patterns the tension of the slide can be adjusted. Model A.G.l (£l 13s.), a simple general-purpose rule, has the usual $A, B, C, D$ scales, and also scales for reciprocals, cubes and mantissæ; additional red lines on the cursor provide for finding areas of circles of given diameter.

Erratum. In the communication entitled "Cellular Permeability of Yeast to Metallic Ions", by E. Quagliozzi and A. Rescigno, published in Nature of July 5, p. 35, the first equation should read:

$$
\frac{V}{L} \frac{\mathrm{d} x}{\mathrm{~d} t}=-v \frac{x}{L b / V}+v \frac{\left(x_{0}-x\right) V / L}{a} ;
$$

and the second should read:

$$
\frac{x}{x_{0}}=\frac{a \cdot \exp \left(-v \frac{a+b}{a b} t\right)+b}{a+b} .
$$

The second reference in the footnote should be disregarded. 